Military Technical College Kobry El-Kobbah, Cairo, Egypt

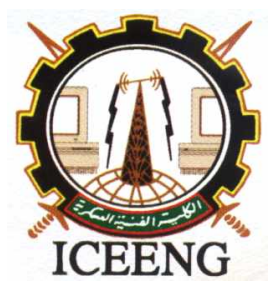

\author{
$6^{\text {th }}$ International Conference \\ on Electrical Engineering \\ ICEENG 2008
}

\title{
Architecture with microcontroller for the technical state evaluation of the switchgears contacts
}

By

C. Pancu*

A. Baraboi*

M. Adam*

A. Pleşca*

\section{Abstract:}

Electroerosion estimation of the contacts realised in operation leads to an overestimation inducing a supplementary maintenance. In this paper is shown an architecture with microcontroller for the technical state evaluation of the switchgears contacts, from electroerosion point of view. This approach has the advantage that the architecture can be used, also, for the monitoring of the some cinematic parameters for the operating mechanism like as: closing speed, opening speed, closing time, opening time, the energy accumulated in the acting mechanism and others.

\section{Keywords:}

Electroerosion, switchgear, architecture, microcontroller. 


\section{Introduction:}

In the technical state evaluation of the switchgears, it's very important to know the contacts' quality, from the point of view of their electroerosion.

Electroerosion depends on the switching number and the currents values at which these switching have been realised, the arc time of each switching, but not only. Also, the thermo-physical parameters of the contacts' materials, the environment type from the arc extinction chamber and the ambient temperature have a great importance in the technical state evaluation of the switchgears contacts.

\section{Estimation methods for the contacts electroerosions:}

The electric arc between circuit breaker contacts makes a contacts electroerosion which depends on the current and the developed energy in column of arc, respectively. The material's volume resulted under the influence of the current interruption is calculated with:

$\mathrm{v}=\mathrm{k} \cdot \int_{0}^{\mathrm{t}} \mathrm{i} \cdot \mathrm{dt}$

where: $\mathrm{i}$ is the RMS value of the switched current in $[\mathrm{kA}], \mathrm{t}-$ the existence time of the electric arc in [ms], k-material constant.

In the case of HV circuit breakers for which the extremities of the electric arc remain practically fixed on the surface of mobile and fix contacts on the existence time of the electric arc, the mass wear $\mathrm{m}$, expressed in [mg], is given by the relation, [1]:

$\mathrm{m}=\mathrm{c} \cdot \mathrm{I}^{\mathrm{d}} \cdot \mathrm{t}$,

where: I is the RMS value of the switched current in $[\mathrm{kA}], \mathrm{t}-$ the existence time of the electric arc in [ms], c, d-constants that depend on the contacts' material (for example, in the case of copper-wolfram contacts, $c=0,274, d=1,81$ ).

In order to appreciate the electroerosion effect of contacts and the switching number of circuit breaker, respectively, some relations which don't take in consideration the existence time of electric arc, are used.

In this sense, Figure 1 shows an equivalent number of breaking operations as a function of breaking current for a $\mathrm{SF}_{6}$ puffer type circuit breaker. $\mathrm{N}_{\mathrm{e}}$ represents an equivalent number of breaking operations which has the same effect such as a single breaking operation under $0,5 \mathrm{I}_{R}$ (were $\mathrm{I}_{R}$ is rated breaking current of circuit breaker and $\mathrm{I}$ breaking current). For values under $0,35 \mathrm{I}_{\mathrm{R}}, \mathrm{N}_{\mathrm{e}}$ is calculated with following relations: 
$\mathrm{N}_{\mathrm{e}}=1.83\left(0.35 \frac{\mathrm{I}_{\mathrm{R}}}{\mathrm{I}}\right)^{3}$,

and for values above $0,35 \mathrm{I}_{\mathrm{R}}$ with:

$\mathrm{N}_{\mathrm{e}}=\left(0.5 \frac{\mathrm{I}_{\mathrm{R}}}{\mathrm{I}}\right)^{1.7}$

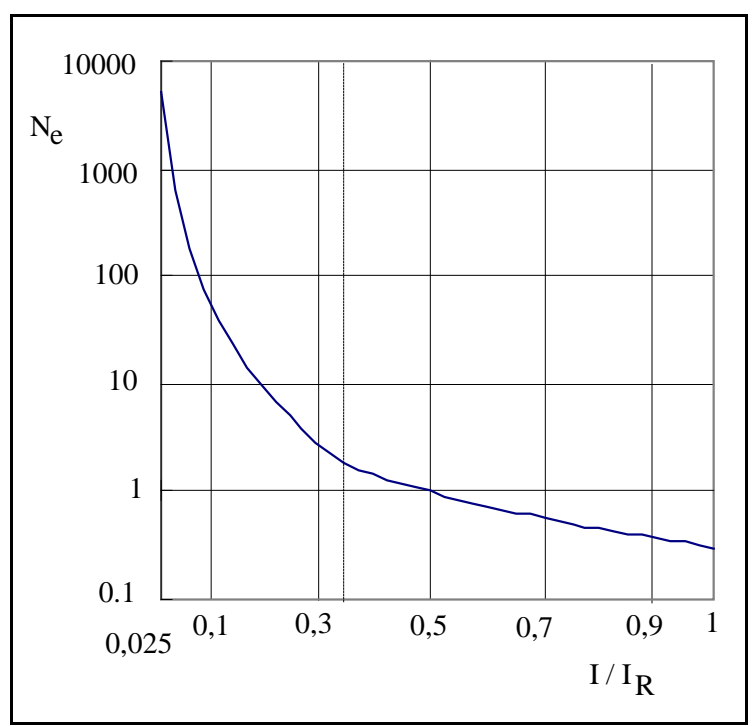

Figure (1): Equivalent number of breaking operations as a function of breaking current for a SF6 puffer type circuit breaker

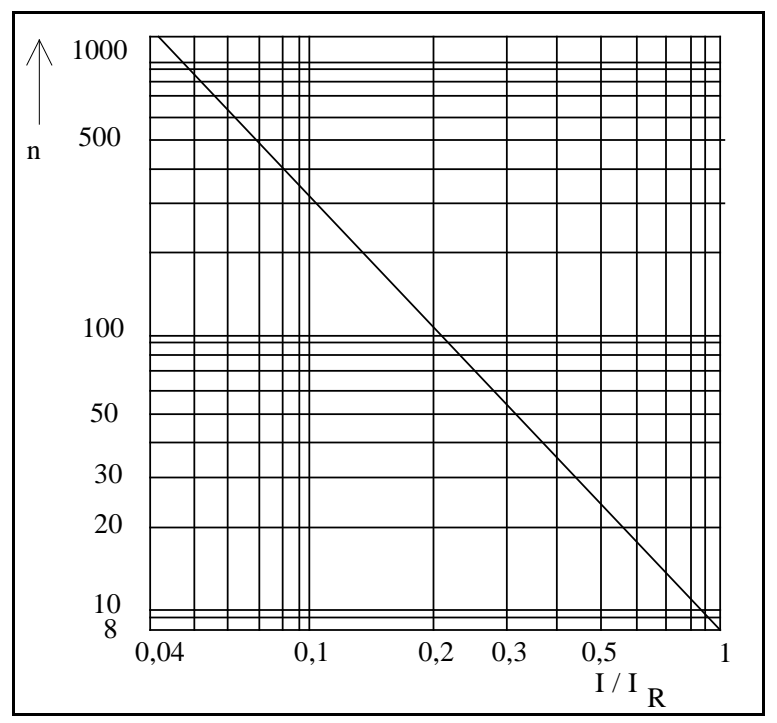

Figure (2): Maintenance diagram for the HV circuit breaker with SF6 type H14P4O 
For the monitoring of contacts electroerosion some electrical equipment constructors give us the maintenance diagrams as functions of breaking current.

Figure 2 shows the maintenance diagram for the $123 \mathrm{kV}$ circuit breakers with SF6 manufactured in Romania where they are: $n$-the number of switching; $I_{R}$-rated breaking current. It remarks that the limit number of switching at $\mathrm{I}_{\mathrm{R}}$ of $40 \mathrm{kA}$ is 8 .

If we know exactly the existence time of electric arc and evolution of breaking current, we may have a very good knowledge about the contacts electroerosion. Starting from this aim we have proposed a method to estimates these parameters.

Figure $3 \mathrm{a}$ shows the place of circuit breaker in electrical substation, while Figure $3 \mathrm{~b}$ shows the equivalent electrical schema.

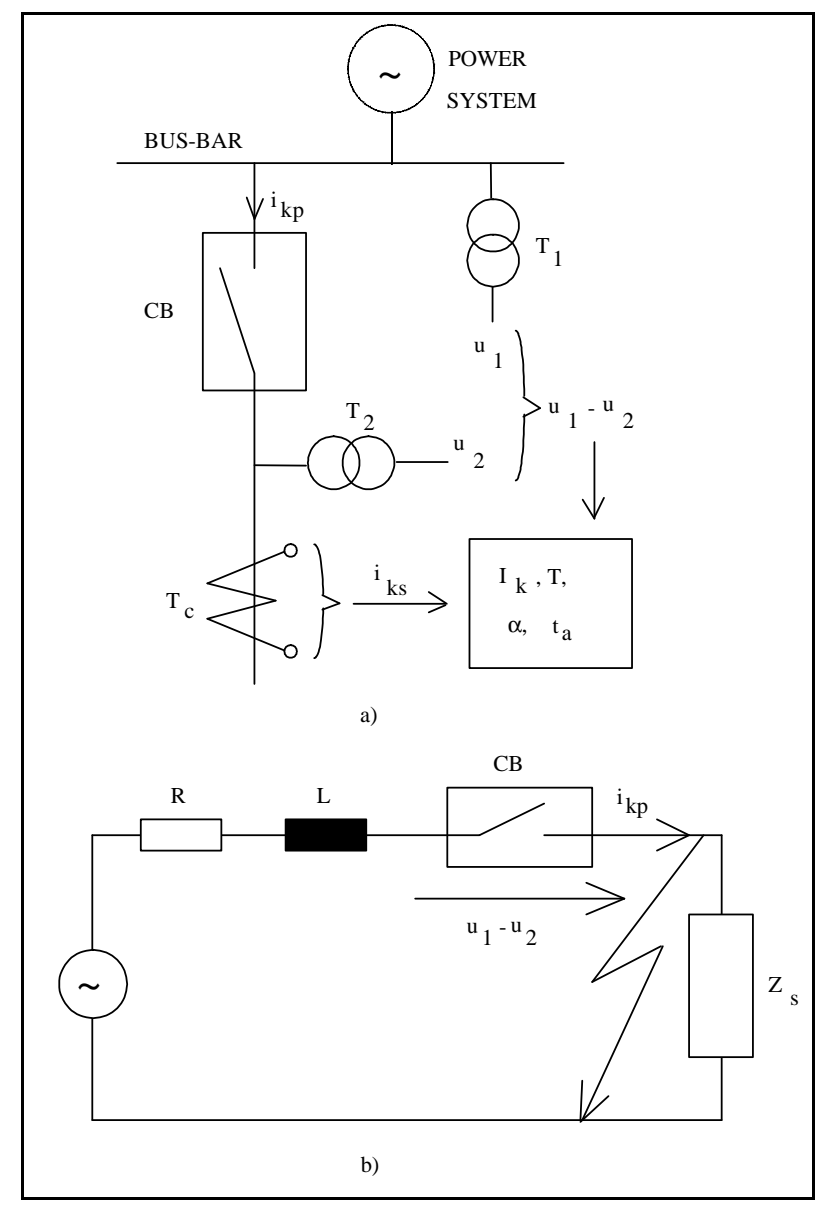

Figure (3): Place of the circuit breaker in electrical substation

The current monitoring through circuit breaker is realised with a current transformer Tc. The existence time of electric arc is estimated knowing the appearance and extinction moments of the electric arc. The beginning moment isn't discerned from the current curve but is possible by monitoring of the differential voltage $\mathrm{u}_{2}-\mathrm{u}_{1}$ from secondary windings of voltage transformers $\mathrm{T}_{2}, \mathrm{~T}_{1}$, Fig.2a. The extinction moment is in accordance with the breaking of short-circuit current. 


\section{Architecture with microcontroller for electroerosion estimation:}

The RISC (Reduced Instructions Set Computer) microcontroller is a powerful tool that provides a highly flexible and cost-effective solutions to many embedded monitoring and diagnostic applications. The architecture has been made around of an Atmel ATmega8 AVR microcontroller, under the shape of an integrate device, Figure 5, with principle scheme presented in Figure 4, [2].

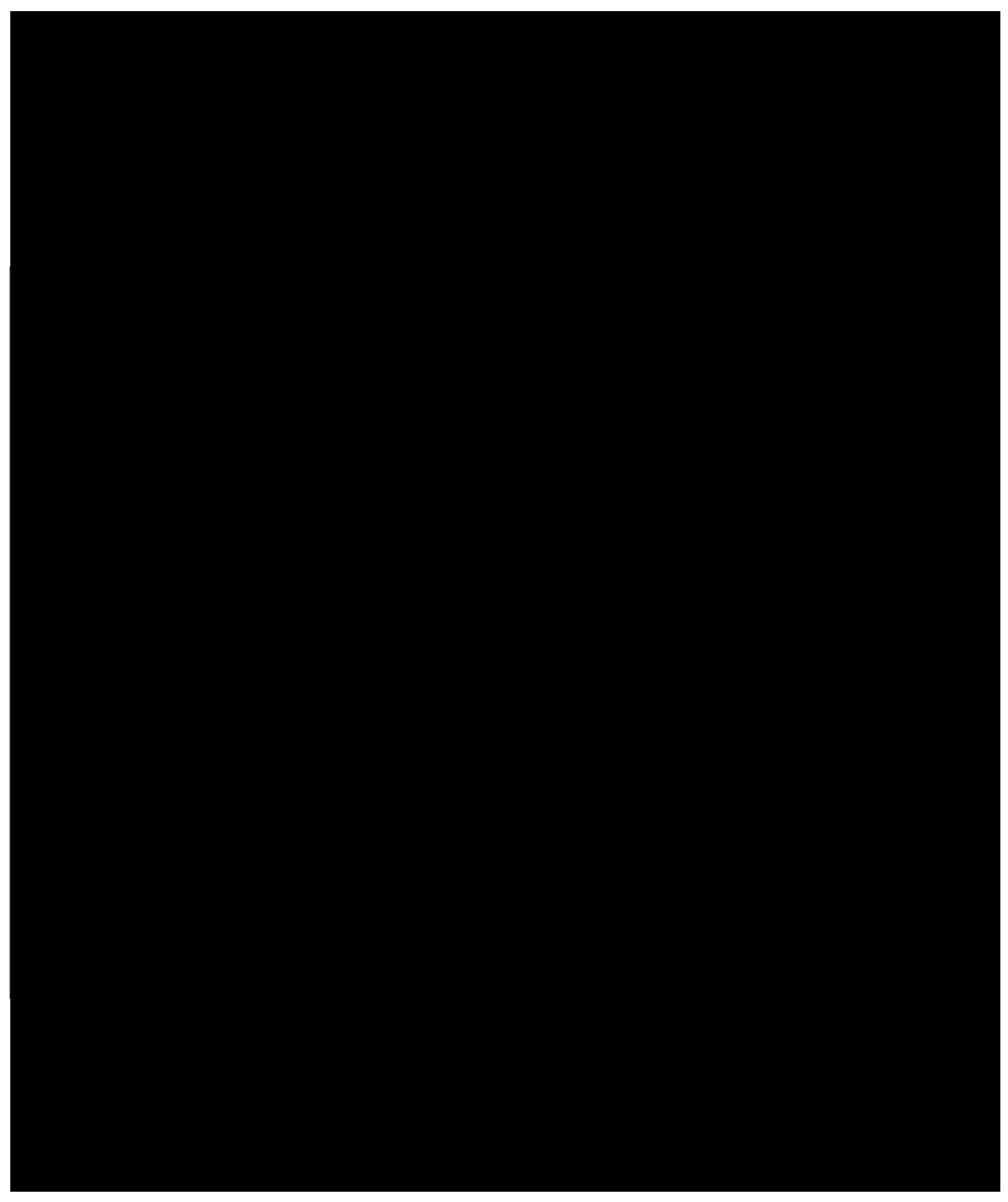

Figure (4): Principle scheme of the integrated device

In additional to the microcontroller, the device includes and a LCD for local display of the monitored parameters, a RS232 serial interface for bidirectional communication with a PC and four push buttons for local selection of various functions by the user. In order to obtain an improved resolution of the measurements received from the transformers, these have been amplified using LM324N operational amplifiers, having a specific amplifying rate for each channel. 
In EEPROM memory of the ATMega8 AVR microcontroller, from the realised architecture, can be stored different measurements and settings.

For the serial communication with other periphericals, the ATMega8 AVR microcontroller includes a specialised circuit USART (Universal Synchronous and Asynchronous serial Receiver and Transmitter), [4]. For the TTL/RS232 compatibility, the hardware/software structure is equipped with a specialised circuit, HIN202.

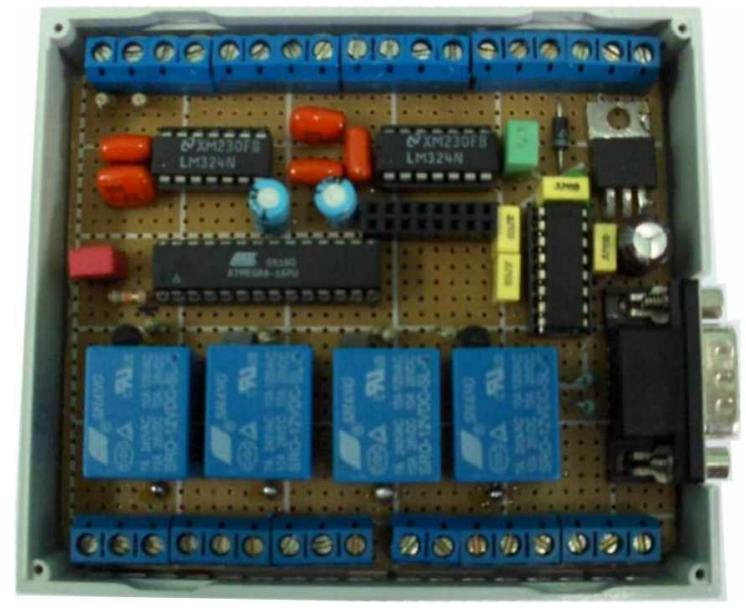

Figure (5): Integrated device

\section{Conclusions:}

In the technical state evaluation of the switchgears, it's very important to know the contacts' quality, from the point of view of their electroerosion.

The proposed architecture, realised under the shape of an integrated device, has the advantage that can be used for electroerosion estimation and also, for the monitoring of the some cinematic parameters for the operating mechanism like as: closing speed, opening speed, closing time, opening time, the energy accumulated in the acting mechanism and others. Through this approach, it is possible the local display of the monitored parameters and their transmission at a PC for an ulterior processing.

\section{References:}

[1] M. Adam, A. Baraboi, P. Leonte, A possibility to estimate the contacts electroerosion for the circuit breakers in service, Eighth International Conference "Switching Arc Phenomena", Lodz, Poland, P.226-229, 1997

[2] Adam M., Pancu C., Baraboi A., Structuri hardware-software în construcția echipamentelor electrice inteligente, Editura Venus, Iaşi, Romania, 2006

[3] * * *, Intrerupătoare cu hexafluorură de sulf tip H14 P40, H17 P40, Electroputere, Craiova, Romania, 1988.

[4] ***, AVR microcontroller with programmable flash, Rev. 1042H-AVR-04/03 